\title{
A Perspective on the Economy: Three Years of Expansion
}

\author{
JEAN M. LOVATI
}

M

ARCH 1978 marked the third anniversary of the current economic expansion. Over the course of the expansion, growth in production of goods and services has been comparable to the average output growth in similar three-year periods of prior recoveries. By other measures, however, this recovery has not been average. Growth in employment, for example, has been exceptional. Moreover, the level of unemployment and the pace of inflation both have remained relatively high.

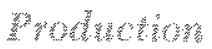

In the most recent quarter, production of goods and services, as measured by real gross national product, declined at a 0.6 percent ammal rate. This recent decline reflected the pervasive effects of severe winter weather early in 1978 combined with an extended strike in a major portion of the coal industry. The effects of these factors, while having a debilitating impact on the economy, are temporary in nature. The decline in aggregate production early this year should not be regarded as a signal of a failing expansion, as economic fundamentals remain strong.

Over the entire expansion, from first quarter 1975 to first quarter 1978 , real gross national product increased at a 5.1 percent annual rate. This is about average compared to other postwar recoveries. During the first three years of four previous expansions, output grew, on average, at a 5.6 percent rate ${ }^{1}$ (see Table I).

While growth seems to be on track with other recoveries after three years, the path of the current recovery has taken on its own unique characteristics. Initially, the economy expanded at a rapid pace, experiencing a 9 percent rate of growth in real output

'Postwar expansions used for comparison in this article are those whose troughs are October 1949, May 1954, February 1961, and November 1970. The expansion beginning in April 1958 was eliminated because it lasted only two years.

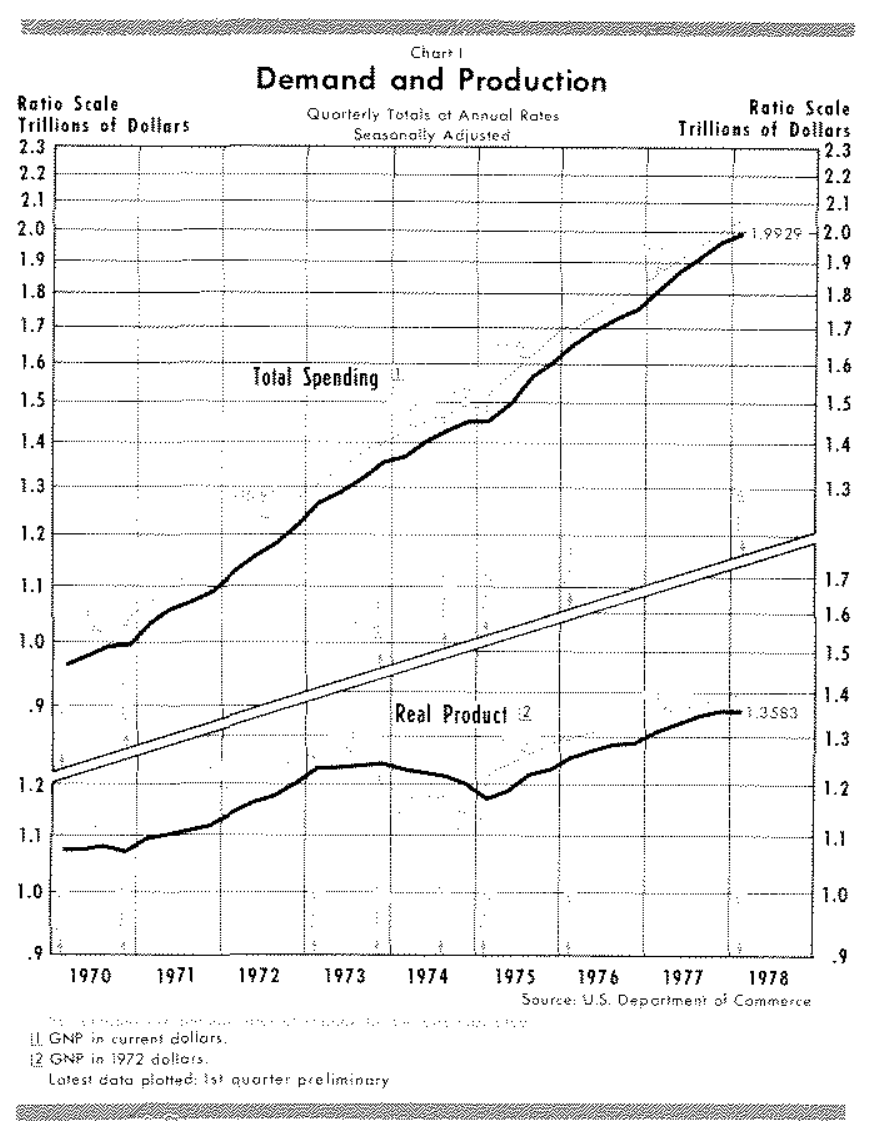

of goods and services between the first and third quarters of 1975 (Chart I). During this time, inventory stocks continued to decline, but did so at a reduced rate. This slowing down of inventory decumulation as well as the dramatic rise in real final sales were reflected in the exceptional rate of growth early in the recovery. Over the first year of expansion, real output grew 7 percent.

The second year of the recovery was marked by more sustainable growth. Production of goods and services advanced 4 percent between first quarter 1976 and first quarter 1977. Real final sales expanded steadily, registering a fairly strong 4.4 percent gain in the expansion's second year. 


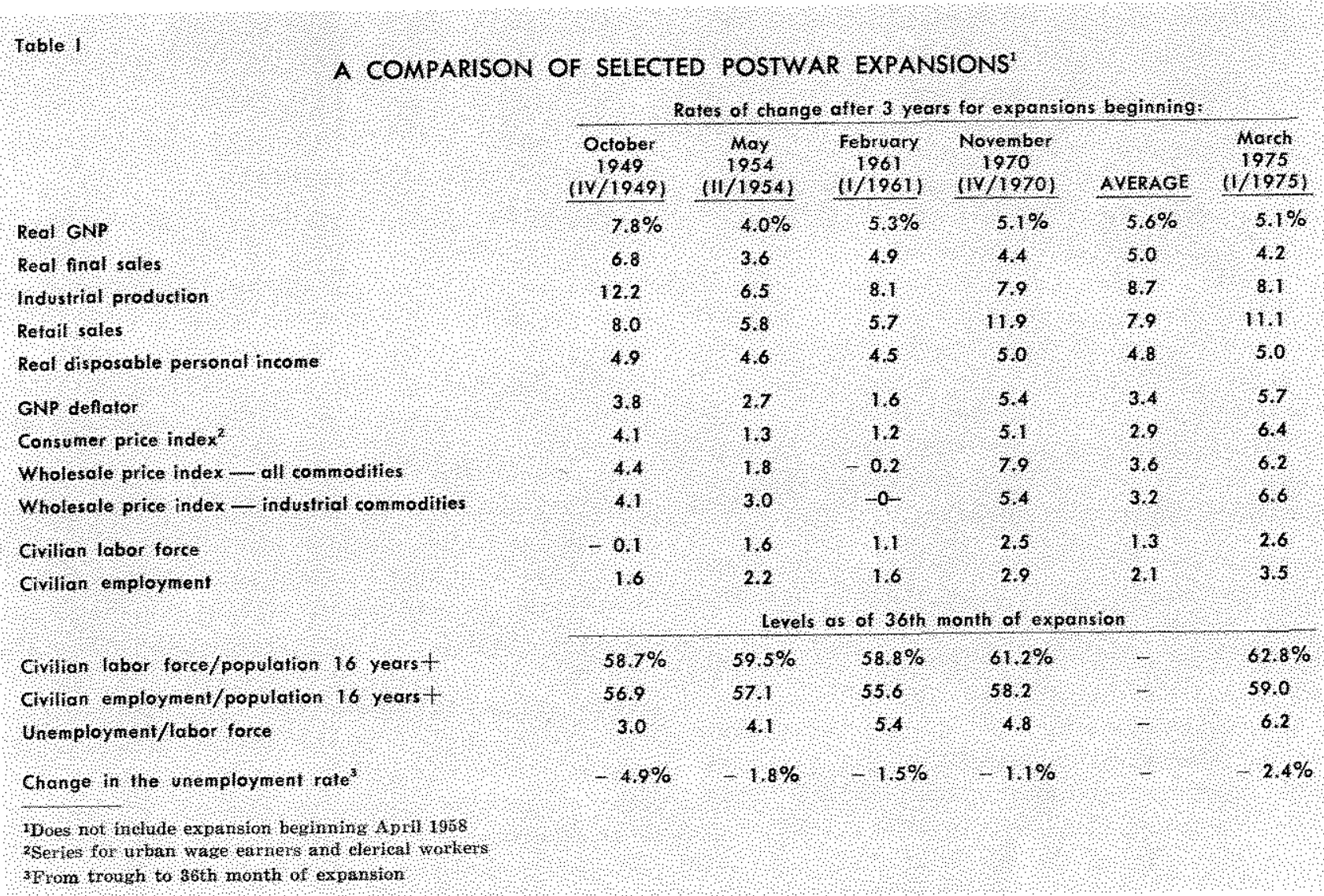

In the latter part of 1976 , the economy experienced some inventory adjustments which induced a slowdown in the growth of total output. At the end of the year, the ratio of inventories to monthly sales in manufacturing and trade industries fell precipitously. The situation was compounded by severe weather conditions in the first quarter of 1977. Such complications limited inventory rebuilding and output growth. These temporary effects were offset, however, by faster growth in the two subsequent quarters, so that the recovery regained its footing and achieved a 5.7 percent increase over 1977 as a whole.

Many of the same factors were at work at the end of 1977 and the beginning of 1978. Inventories again declined relative to monthly sales. As noted above, severe weather combined with the coal strike temporarily hampered production. Despite these factors, output grew 4 percent in the third year of the expansion.

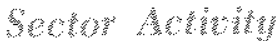

The over-all expansion has been reflected in substantial growth of spending by different sectors in the economy at different stages of the recovery. In the first year, for example, consumer spending made sub- stantial advances, while spending by businesses on plant and equipment and by the Federal Government were rather sluggish. As the expansion progressed in the next two years, growth in these sectors gradually reversed.

Personal consumption expenditures, which comprise about 64 percent of gross national product, increased rapidly early in the expansion, advancing 13 percent in the first year of the recovery as substantial gains were made in personal income. Even after accounting for inflation, real household spending registered a 7 percent growth between first quarter 1975 and first quarter 1976. Spending on consumer durables, which increased 25 percent in the first four quaters of the recovery, was boosted by heavy purchases of autos and appliances. Expenditures on nondurable consumer goods rose 9 percent over the same period. While remaining relatively strong, growth of consumption expenditures has slowed from initial rates in the recovery. Since the first quarter of 1976 , spending on consumption goods and services grew in nominal terms at a 10 percent annual rate.

Investment in residential structures has also made significant gains over the course of the current expan- 
sion. Residential housing advanced at a nominal rate of 28 percent per year over the three years of expansion. Housing starts surpassed 2 million units in 1977, with single-family starts exceptionally strong. This strong demand for housing partially reflected an attempt to make up for new house purchases postponed during the recession. Between second quarter 1974 and first quarter 1975, investment in residential structures had declined at more than a 21 percent rate. Recent strength of demand for housing is probably also influenced to some extent by homebuyers' uncertainty about future home prices. As housing prices have risen sharply in the last several years, ${ }^{2}$ some housing purchases were based on the assumption that new homes would become even more expensive relative to income in the future.

Spending on plant and equipment, on the other hand, demonstrated little strength during the first year of the recovery, growing 4 percent in nominal terms. This relatively slow growth in investment spending was due in large part to continued business uncertainty resulting from the indefinite status of various Government regulations, proposed changes in Federal energy and tax programs, and the future course of inflation. Higher replacement costs and lower productivity of capital goods due to higher energy costs have impeded growth of capital outlays. Inflation, combined with the tax structure, has lowered the yield on, and increased the cost of obtaining the necessary funds for a given investment program, thus eroding incentives to invest. ${ }^{3}$ Recently, however, business fixed investment has shown signs of renewed strength. Since the fourth quarter of 1976 , plant and equipment spending has advanced at about a 14 percent rate.

Govermment purchases of goods and services showed little strength in the first two years of the expansion. Between first quarter 1975 and first quarter 1976, real Government spending advanced 2 percent and over the following four quarters declined slightly. This pattern has been reversed, however, since the begimming of 1977 . Real Govermment spending has increased more than 4 percent in the past year. The recent rise in the growth of Government spending has been sharpest among state and local governments, which coincides with increased grantsin-aid through the Federal Government's 1977 eco-

\footnotetext{
2Housing prices, as measured in the consumer price index have risen at an 8 percent annual rate since 1970 .

see John A. Taton and James E. Turley, "Inflation and Taxes: Disincentives for Capital Formation," this Review (January 1978), wp. $2-8$.
}

nomic stimulus program. This program includes local public works, public service employment, and other employment and training programs.

\section{Labor Worke Dovelomments}

A significant characteristic of the present expansion has been the rapid growth of employment. In the 36 months of the expansion, civilian employment has grown at an annual rate of 3.5 percent. This growth is exceptionally high by historical standards. Over comparable 36 -month periods in past expansions, civilian employment grew at an average 2.1 percent rate.

Labor force growth also has been rapid over the recovery. A record 62.8 percent of the civilian noninstitutional population aged 16 and over were members of the labor force in March 1978. In other periods of relatively high employment, 1956 and $1967-69$ for example, 60 and 59.8 percent, respectively, of the working-age population were in the labor force. In the three years of the current expansion, the civilian labor force has grown at a 2.6 percent rate, twice the average rate of growth achieved during the first three years of previous expansions. Demand for labor has been relatively strong, so that many in the labor force have been placed in jobs. The number of employed persons in the working-age population reached a postwar peak of 59.0 percent in March, higher than at any time in the prior 29 years.

Significant progress has been made in lowering the unemployment rate over the past three years. The unemployment rate declined from 8.6 percent in March 1975 to 6.2 percent in March $1978^{4}$ (see Chart II). Despite such progress, the rapid growth in the labor force left more than 6.1 million workers currently recorded as being unemployed.

The level of the unemployment rate reflects various factors, including structural changes in the composition of the labor force, which have tended to maintain its relatively high position. The labor force now contains relatively more women and teenagers than heretofore. Adult women comprised 37.1 percent of the labor force as of March of this year, a record high. Moreover, while the participation of women has been increasing throughout the postwar period, it has intensified within the past five years. Participation of adult women (aged 20 and over) in the labor force reached a peak of 49.1 percent in March, compared to an average participation rate of 37.8 percent

${ }^{\ddagger}$ In April, the unemployment rate fell to 6.0 percent. 


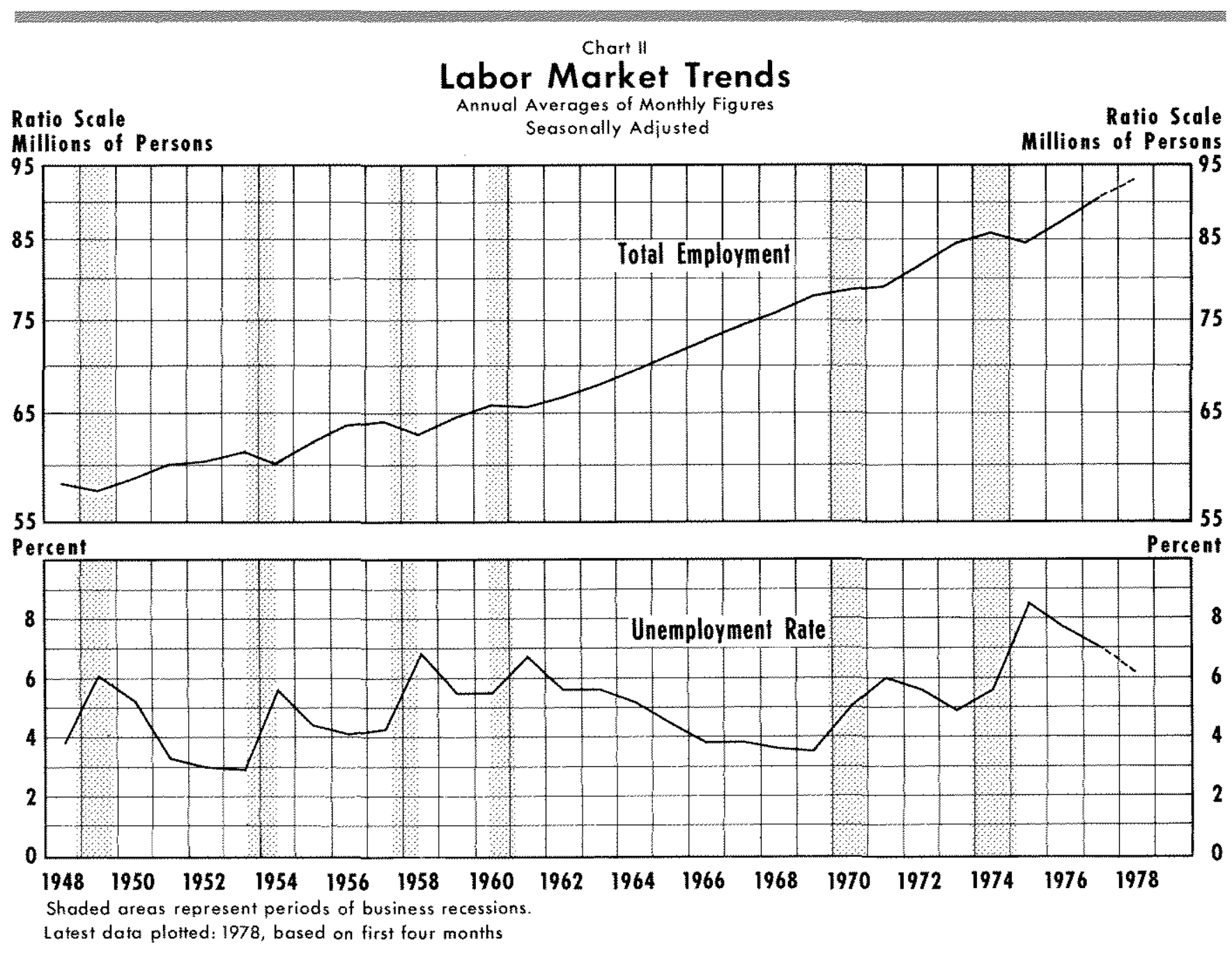

in prior periods of expansion. ${ }^{5}$ Much of the impetus for the recent rise can be attributed to married women (spouse present) whose participation in the labor force has risen over 3.6 percentage points since 1974. Of these women, many have small children (infant to 5 years old), a characteristic whose inhibiting influence on labor market participation seems to be diminishing.

Teenagers also account for a larger proportion of the labor force than in previous periods. Labor force participation of workers aged 16-19 stood at 56.7 percent in March, nearly the highest in recent history.

Partially because of the level of skills of these groups of workers, plus the restrictions of the minimum wage and the tenuous nature of labor force

Participation rates measure the proportion of persons in a specific population group that are in the civilian labor force. attachment in the case of teenagers, higher rates of unemployment are generally experienced by women and teenagers. Due to the increased size of these groups, their unemployment rates are weighted more heavily which, in turn, tends to raise the average level of the overall unemployment rate. In March 1978, unemployment rates for adult women and teenagers were 5.8 and 17.3 percent, respectively. In the same month, adult men had an unemployment rate of 4.5 percent.

According to current data, the average duration of unemployment is less than 13 weeks. This is well within the present maximum limit for receipt of unemployment compensation. The broad scope of benefit programs, coupled with savings and other sources of aid such as food stamps, tend to reduce. the economic hardship suffered by the unemployed. However, such unemployment programs also tend to reduce incentives for the jobless to obtain work, pre 
serving a high number of unemployed, even under fairly tight labor market conditions. ${ }^{B}$

\section{wated}

Another feature of the current expansion which distinguishes it from others is the much higher rate of inflation which prevails. The implicit price deflator, a measure of the general level of prices, rose at a 5.7 percent rate over the twelve quarters of this recovery. In the first twelve quarters following the troughs of past recessions, the general level of prices rose an average of 3.4 percent per year.

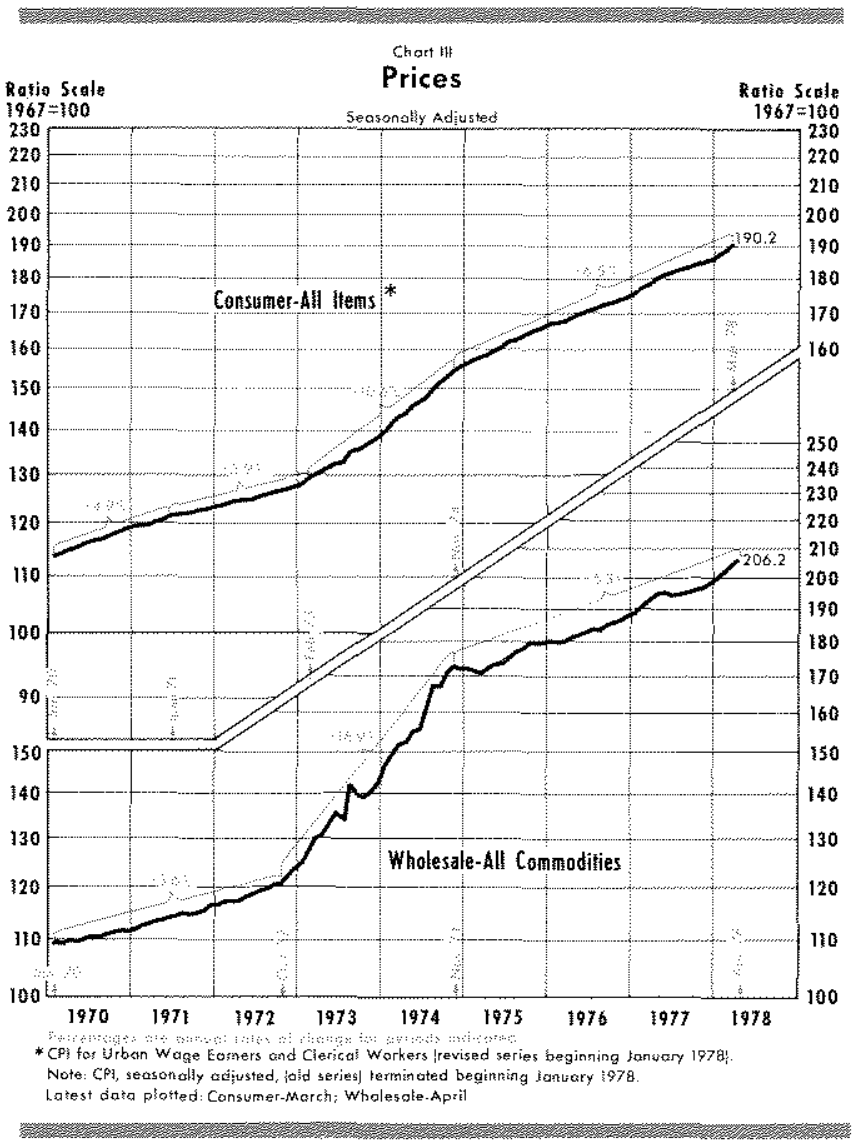

Prices, as measured by the consumer and wholesale price indexes, show a similar pattern. The consumer price index (CPI) ${ }^{7}$ rose at a 6.4 percent rate between March 1975 and March 1978 (Chart III). In the past, however, the CPI averaged a 2.9 percent annual rate of growth over similar recovery periods. On the wholesale level, prices of industrial commodities rose at a 6.6 percent rate in this expansion, compared to an average rate of 3.2 percent in other expansions.

ESee Martin Feldstein, "The Economics of the New Unemployment," The Public Interest (Fall 1973), pp. 3-42.

TThis CPI refers to the series for urbar wage eamers and clerical workers.
The difference between the inflation experience in the current recovery and that in previous recoveries primarily reflects differences in the growth of money. Growth of prices is primarily determined by the trend growth rate of money. In the five years preceding this recovery, the money stock grew at a 6.2 percent rate, greater than money had grown in the five years prior to any other postwar recovery. While money stock increased at a 5.7 percent rate between November 1966 and November 1970, in the corresponding periods preceding the expansions beginning May 1954 and February 1961, money had grown at only 3.1 and 1.4 percent rates, respectively. Moreover, money growth has been accelerating since the current recovery began, reaching a 7.3 percent rate in the period from the third quarter 1976 to first quarter 1978 (Chart IV).

This expansion in the money supply reflects growth in the monetary base, its prime determinant, which has shown a marked acceleration during the recovery. In the first two years of this expansion, the monetary base had grown at an 8.2 percent rate, from the 7.7 percent rate recorded in the previous three quarters. In the expansion's third year, the base growth accelerated to a 9.3 percent rate.

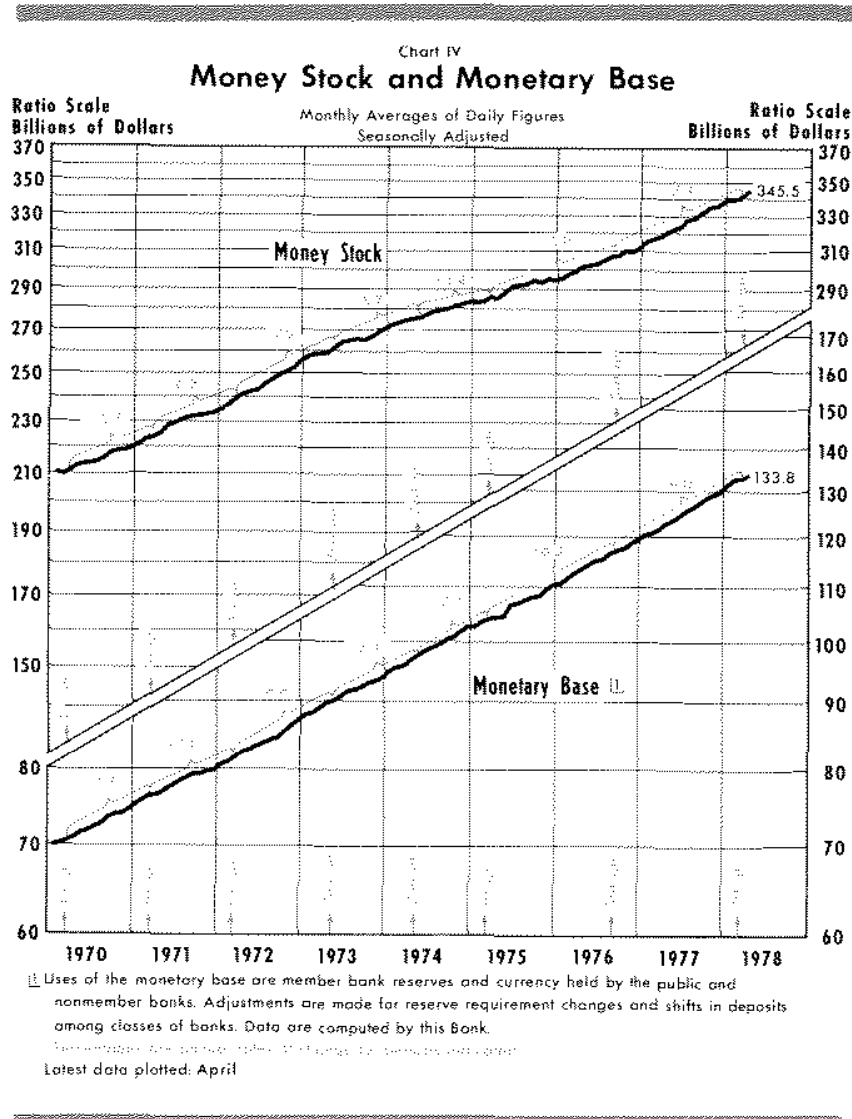

Page 6 


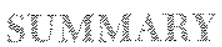

The current expansion has reached the average length of other postwar recoveries and, in terms of production of real goods and services, has posted about the same rate of growth from the trough as have other expansions. However, specific characteristics of the current situation are unique. Plagued by severe winters and temporary shortages of energy, growth of real output has been hampered at various stages of this recovery. Inventory investment, although accelerating recently, has also been impeded by various adverse factors. Business fixed investment expenditures still remain low relative to other recoveries.

While the expansion has been reffected primarily in growth of private consumption, investment and Government expenditures may take on more prominent roles in the future. Investment expenditures as well as Federal purchases of goods and services have rebounded from their sluggish behavior in the earlier stages of the recovery. During 1977, gross private domestic investment, after accounting for inflation, grew nearly 17 percent; real Federal Government purchases advanced at a 10 percent rate over the last three quarters of the year.

Housing growth, on the other hand, which has shown exceptional strength during the recovery, may be tempered due to rising interest rates and exhaustion of "pent-up" demand forces. Rates on short-term market instruments, such as 3-month Treasury bills, have risen to levels equal to the ceiling limits on saving and loan time deposit accounts. If disintermediation becomes a serious problem, the housing sector may suffer more serious slowing.

Two problems, formerly an unusual combination, are likely to continue to be characteristic of the prevailing economic environment. The unemployment rate, which has been primarily influenced by structural and supply factors, is generally expected to remain relatively high. Inflation is also not likely to show any slowing in 1978. Based on past rates of monetary growth, inflation can be expected to run in the neighborhood of 6 percent during this year.

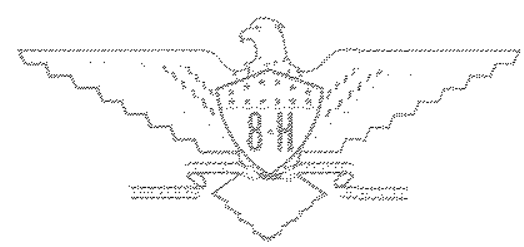

